\title{
Pengaruh Gangguan Kecemasan Terhadap Hasil Belajar Siswa di SMK Negeri 1 Makassar
}

\author{
Nuraisyiah $^{1 *}$, Nurdiana ${ }^{2}$, Muhammad Imam Ma'ruf ${ }^{3}$ \\ ${ }^{1}$ Program Studi Pendidikan Akuntansi, Fakultas Ekonomi Universitas Negeri Makassar \\ ${ }^{2}$ Program Studi Pendidikan Ekonomi, Fakultas Ekonomi Universitas Negeri Makassar \\ ${ }^{3}$ Program Studi Ekonomi Pembangunan, Fakultas Ekonomi Universitas Negeri Makassar \\ ${ }^{1}$ Email: nuraisyiah@unm.ac.id, ${ }^{2}$ Email: diana@unm.ac.id, \\ ${ }^{3}$ Email: muhammadimammaruf@unm.ac.id \\ *Corresponding author
}

\begin{abstract}
This study aims to determine the effect of anxiety disorders on student learning outcomes in accounting subjects class XI at SMK Negeri 1 Makassar. This study uses questionnaires and documentation in collecting data. This study uses descriptive percentage analysis, and statistical analysis for statistical analysis of data. Statistical analysis of data includes Simple Linear Regression Analysis, and t-test. The results showed that anxiety disorders on student learning outcomes in class XI accounting subjects at SMK 1 Makassar through nine indicators namely: tense, confused, worried, difficult to concentrate, unable to sleep, heart palpitations, excessive cold sweat, frequent trembling, and Mules' stomach has a negative and significant effect. This means that if students experience anxiety disorders it will reduce student learning outcomes.
\end{abstract}

Keywords: Anxiety Disorders; Student Learning Outcomes

\begin{abstract}
Abstrak. Penelitian ini bertujuan untuk mengetahui pengaruh gangguan kecemasan terhadap hasil belajar siswa pada mata pelajaran akuntansi kelas XI di SMK Negeri 1 Makassar. Penelitian ini menggunakan angket dan dokumentasi dalam mengumpulkan data. Penelitian ini menggunakan Analisis deskriptif persentase, dan analisis statistic untuk analisis statistik data. Analisis statistik data mencakup Analisis Regresi Linier Sederhana, dan Uji-t. Hasil penelitian menunjukkan bahwa gangguan kecemasan terhadap hasil belajar siswa pada mata pelajaran akuntansi kelas XI di SMK 1 Makassar melalui sembilan indikator yaitu: tegang, bingung, khawatir, sukar berkonsentrasi, tidak dapat tidur, jantung berdebar, keluar keringat dingin berlebihan, sering gemetar, dan perut mules berpengaruh negatif dan signifikan. Hal ini berarti bahwa jika siswa mengalami gangguan kecemasan maka akan menurunkan hasil belajar siswa.
\end{abstract}

Kata Kunci: Gangguan Kecemasan; Hasil Belajar Siswa

\section{PENDAHULUAN}

Dalam kehidupan sehari-hari, kita banyak mengalami peristiwa yang mungkin menimbulkan gangguan kecemasan. Sebenarnya gangguan kecemasan adalah reaksi yang dapat dialami siapapun. Misalnya menghadapi kuis mendadak, ataupun menunggu angkutan umum yang terlambat sementara harus pergi kesekolah. Timbulnya gangguan kecemasan yang paling besar di sekolah pada semua tingkat adalah pada waktu siswa menghadapi tes atau ujian, hasil tes akan mempengaruhi keputusan pendidikan yang akan datang, sehingga tes cenderung menimbulkan gangguan kecemasan pada setiap siswa (Fausiah, 2014:73).

Gangguan kecemasan memiliki karakteristik berupa munculnya perasaan takut dan kehati-hatian atau kewaspadaan yang tidak jelas dan tidak menyenangkan. Gangguan kecemasan sering kali disertai dengan gejala fisik seperti sakit kepala, jantung berdebar cepat, kelelahan, berkeringat, dada terasa sesak, sakit perut, atau tidak tenang dan tidak dapat duduk diam. Gejala-gejala gangguan kecemasan yang muncul dapat berbeda-beda pada masing-masing orang (Fausiah, 2014:74). 
Gangguan kecemasan terbagi atas dua bagian, yaitu kecemasan sebagai suatu sifat (trait anxiety), kecenderungan pada diri seseorang untuk merasa terancam oleh sejumlah kondisi yang sebenarnya tidak berbahaya, dan kecemasan sebagai suatu keadaan (state anxiety), yaitu suatu keadaan atau kondisi emosional sementara pada diri seseorang yang ditandai dengan perasaan tegang dan kekhwatiran yang dihayati secara sadar subyektif, dan meningginya sistem saraf otonom (Slameto, 2013:185).

Menurut Zeider dalam Prawitasari (2012:79) bahwa problem utama siswa dengan tingkat gangguan kecemasan yang tinggi adalah bahwa mereka tidak menguasai secara bagus tentang pokok pelajaran di bagian awal, dan akibatnya mereka juga mengalami kesulitan ketika mempelajari pokok pelajaran yang selanjutnya, dan akibat yang lebih jauh adalah mereka mengalami peningkatan kecemasan pada saat mereka mengerjakan tes.

Agar memperoleh hasil yang optimal, proses belajar mengajar harus dilakukan dengan sadar dan sengaja serta terorganisasi dengan baik. Menurut Hamalik (2006:30) bahwa "Hasil belajar adalah bila seseorang telah belajar akan terjadi perubahan tingkah laku pada orang tersebut, misalnya dari tidak tahu menjadi tahu dan tidak mengerti menjadi mengerti”. Hal ini agar siswa sebagai generasi bangsa dapat berperilaku yang rasional dan bertanggung jawab sebagai implementasi dari pemahaman yang diperolehnya dalam proses belajar (Rahmatullah, 2018).

Menurut Syah (2013:216) bahwa "Hasil belajar adalah pengungkapan hasil belajar ideal yang meliputi segenap ranah psikologis yang berubah sebagai akibat pengalaman dan proses belajar siswa". Hasil belajar dapat dilihat dari berbagai aspek indikator pembelajaran yaitu aspek kognitif, afektif, dan psikomotorik.

Mata pelajaran akuntansi merupakan mata pelajaran yang membutuhkan analisis yang mendalam pada setiap transaksi semua siklusnya. Oleh karena itu, dalam proses pembelajaran akuntansi siswa merasa kesulitan dan tegang pada saat proses belajar. Sehingga guru harus mampu mengelola pembelajaran di dalam kelas agar siswa tidak merasa kesulitan dan tegang pada saat proses pembelajaran. Berikut gambaran mengenai gangguan kecemasan selama proses belajar mengajar dan hasil belajar siswa kelas XI Akuntansi 3 di SMK Negeri 1 Makassar Tahun Ajaran 2017/2018.

Tabel 1. Tingkat Gangguan Kecemasan dan Nilai Rata-rata Ujian Tengah Semester Siswa Kelas XI Akuntansi 3 Semester Genap Tahun Ajaran 2017/2018 di SMK Negeri 1 Makassar.

\begin{tabular}{lccc}
\hline \multicolumn{1}{c}{ Gangguan Kecemasan } & $\begin{array}{c}\text { Persentase } \\
\text { \% }\end{array}$ & $\begin{array}{c}\text { Hasil belajar } \\
\text { siswa }\end{array}$ & $\begin{array}{c}\text { Nilai } \\
\text { rata-rata }\end{array}$ \\
\hline Tegang & $78 \%$ & & \\
Bingung & $73 \%$ & Kognitif & 67 \\
Khawatir & $74 \%$ & & \\
Sukar berkonsentrasi & $78 \%$ & & \\
Tidak dapat tidur & $69 \%$ & Afektif & \\
Jantung berdebar & $74 \%$ & & \\
Keluar keringat dingin berlebihan & $68 \%$ & & 65 \\
Sering gemetar & $71 \%$ & Psikomotorik & \\
Perut mules & $68 \%$ & &
\end{tabular}

Sumber : SMK Negeri 1 Makassar (data diolah)

Berdasarkan Tabel 1 dapat terlihat bahwa gangguan kecemasan siswa perlu dikurangi karena persentase yang diperoleh rata-rata berada pada gradasi tinggi. Hal ini terlihat dari sembilan indikator gangguan kecemasan, yang menunjukkan persentase tinggi yaitu sebesar $78 \%$ pada indikator tegang dan sukar berkonsentrasi, hal tersebut menghampiri persentase ideal (kriterium) sebesar $85 \%$, begitupun dengan indikator gangguan kecemasan lainnya. Sehubungan dengan itu dilihat dari hasil belajar siswa nilai rata-rata kognitif dan psikomotorik tidak mencapai batas KKM (KriteriaKetuntasan Minimum) yang telah ditetapkan yaitu 70 dan nilai afektif siswa rata-rata B (baik). Hal ini disebabkan karena tingginya tingkat gangguan kecemasan dalam proses pembelajaran.

Menurut Slameto (2013:187) bahwa "Gangguan kecemasan siswa sangat penting 
untuk dihilangkan karena akan berdampak negatif terhadap hasil belajar siswa". Sedangkan menurut King (2010:301) bahwa "Gangguan kecemasan yaitu gangguan psikologis yang mencakup ketengangan motorik (bergetar, tidak dapat duduk tenang, tidak dapat bersantai); hiperaktivitas (pusing, jantung yang berdetak cepat, dan juga berkeringat); dan harapan-harapan dan pikiranpikiran yang mendalam".

Banyak faktor pemicu timbulnya gangguan kecemasan pada diri siswa. Misalnya iklim pembelajaran yang tidak kondusif, pemberian tugas yang sangat banyak, serta penilaian yang ketat dan guru yang terlalu disiplin dapat menjadi faktor penyebab timbulnya gangguan kecemasan. Penelitian yang dilakukan Sarason dalam Slameto (2013:185) bahwa "Siswa dengan tingkat gangguan kecemasan yang rendah lebih baik daripada siswa dengan tingkat gangguan kecemasan yang tinggi dapat mempengaruhi hasil belajar siswa".

\section{METODE PENELITIAN}

Penelitian ini dilakukan di SMK Negeri 1 Makassar Kelas XI yang terdiri dari empat kelas dengan jumlah populasi 130 siswa, sampel yang di gunakan sebanyak 57 siswa dengan metode Proportionate Stratified Random Sampling. Dalam penelitian ini, penulis mendapatkan data yang berupa data kuantitatif. Data kuantitatif adalah suatu karakteristik dari suatu variabel yang nilainilainya dinyatakan dalam bentuk numerik. Data yang diambil penulis adalah skor dari jawaban kuesioner penelitian dan data hasil belajar siswa Semester Genap Tahun Ajaran 2017/2018

Hasil penelitian disajikan dengan lengkap dan sesuai ruang lingkup penelitian. Hasil penelitian dapat dilengkapi dengan tabel, grafik (gambar), dan/atau bagan. Tabel dan gambar diberi nomor dan judul. Hasil analisis data dimaknai dengan benar. Variabel yang digunakan untuk menilai gangguan kecemasan siswa:

Tabel 2. Variabel dan Indikator Penelitian

\begin{tabular}{clll}
\hline Variabel & \multicolumn{1}{c}{ Indikator } & No. Item \\
\hline Gangguan Kecemasan & 1. & Tegang & $1,2,3$ \\
& 2. & Bingung & $4,5,6$ \\
& 3. & Khawatir & $7,8,9$ \\
& 4. & Sukar berkonsentrasi & $10,11,12$ \\
& 5. & Tidak dapat tidur & 13,14 \\
& 6. Jantung berdebar & $15,16,17$ \\
& 7. Keluar keringat dingin berlebihan & $18,19,20$ \\
& 8. Sering gemetar & $21,22,23$ \\
& 9. Perut mules & 24,25 \\
\hline
\end{tabular}
25

Analisis yang digunakan dalam penelitian ini adalah analisis deskriptif persentase, analisis keabsahan data, dan analisis statistik data. Analisis statistik data mencakup Analisis Regresi Linier Sederhana, dan Uji-t.

\section{HASIL DAN PEMBAHASAN Variabel Gangguan Kecemasan}

Berdasarkan tanggapan responden terhadap variabel gangguan kecemasan yang diperoleh dari sembilan indikator, maka gangguan kecemasan untuk pelajaran akuntansi di sekolah di SMK Negeri 1 Makassar dapat di lihat pada Tabel 2.

Tabel 2. Tanggapan Responden tentang Gangguan Kecemasan pada SMK Negeri 1 Makassar

\begin{tabular}{clc}
\hline No & \multicolumn{1}{c}{ Indikator } & $(\%)$ Skor Aktual \\
\hline 1 & Tegang & 61,3 \\
2 & Bingung & 58,8 \\
3 & Khawatir & 69,9 \\
4 & Sukar berkonsentrasi & 73,7 \\
5 & Tidak dapat tidur & 62,6 \\
6 & Jantung berdebar & 66,2 \\
7 & Keluar keringat dingin berlebihan & 52,4 \\
8 & Sering gemetar & 59,3
\end{tabular}


Sumber: Hasil olah data, 2018

Berdasarkan hasil olah data tentang gangguan kecemasan pada pelajaran akuntansi kelas XI SMK Negeri 1 Makassar, terlihat bahwa gangguan kecemasan yang paling tinggi dialami pada indikator sukar berkonsentrasi yang mencapai $73,7 \%$. Hal tersebut disebabkan karena siswa tidak dapat tidur pada malam hari memikirkan tugas yang diberikan oleh guru. Dengan rata-rata skor sebesar $61,4 \%$ atau berada pada kategori cukup. Hal ini menunjukkan bahwa ada rasa kecemasan dalam belajar akuntansi.

Menurut Zeider dalam Prawitasari (2012:79) bahwa problem utama siswa dengan tingkat gangguan kecemasan yang tinggi adalah bahwa mereka tidak menguasai secara

Tabel 4. Hasil Analisis Regresi Sederhana

\begin{tabular}{|c|c|c|c|c|c|c|}
\hline \multicolumn{7}{|c|}{ Coefficients $^{a}$} \\
\hline \multirow[b]{2}{*}{ Model } & & \multicolumn{2}{|c|}{ Unstandardized Coefficients } & \multirow{2}{*}{$\begin{array}{c}\text { Standardized Coefficients } \\
\text { Beta } \\
\end{array}$} & \multirow[b]{2}{*}{$\mathrm{t}$} & \multirow[b]{2}{*}{ Sig. } \\
\hline & & $\mathrm{B}$ & Std. Error & & & \\
\hline \multirow[t]{2}{*}{1} & (Constant) & 2.202 & .126 & & 17.517 & .000 \\
\hline & $\begin{array}{l}\text { Gangguan } \\
\text { Kecemasan } \\
\text { (X) }\end{array}$ & -.160 & .065 & -.313 & -2.448 & .018 \\
\hline
\end{tabular}

a. Dependent Variable: Hasil Belajar

Berdasarkan Tabel 4, maka persamaan regresi yang didapatkan adalah sebagai berikut:

$$
\mathrm{Y}=2,202-0,160 \mathrm{X}
$$

Interpretasi dari model regresi linear sederhana di atas adalah sebagai berikut:

1) Konstanta (a) sebesar 2,202

Berarti tanpa mempertimbangkan pengaruh manapun maka nilai hasil belajar sebesar 2,202 atau dengan kata lain jika gangguan kecemasan sama dengan nol maka nilai hasil belajar sebesar 2,202.

2) Koefisien (b) sebesar $-0,160$

Dari persamaan regresi diperoleh koefisien regresi variabel gangguan kecemasan bernilai negatif yaitu $-0,160$. Hal ini bagus tentang pokok pelajaran di bagian awal, dan akibatnya mereka juga mengalami kesulitan ketika mempelajari pokok pelajaran yang selanjutnya, dan akibat yang lebih jauh adalah mereka mengalami peningkatan kecemasan pada saat mereka mengerjakan tes.

\section{Variabel Hasil Belajar}

Hasil belajar siswa adalah nilai yang telah dicapai dalam proses pembelajaran. Data yang disajikan diperoleh dari nilai ulangan semester genap mata pelajaran akuntansi siswa kelas XI SMK Negeri 1 Makassar Tahun Ajaran 2017/2018. 


\begin{tabular}{|c|c|c|c|c|c|}
\hline \multirow[b]{2}{*}{ Model } & \multicolumn{4}{|c|}{ Model Summary } & \multirow[b]{2}{*}{ Durbin-Watson } \\
\hline & $\mathrm{R}$ & R Square & Adjusted R Square & $\begin{array}{c}\text { Std. Error of the } \\
\text { Estimate }\end{array}$ & \\
\hline 1 & $.413^{\mathrm{a}}$ & .098 & .082 & .02890 & 2.173 \\
\hline
\end{tabular}

a. Predictors: (Constant), Gangguan Kecemasan

b. Dependent Variable: Hasil Belajar

Berdasarkan Tabel 5 menunjukkan bahwa Korelasi Product Moment (r) sebesar 0,413 berarti bahwa antara variabel gangguan kecemasan $(\mathrm{X})$ terhadap hasil belajar siswa (Y) berada pada interval 0,400-0,599 pada kategori sedang. Maka dapat disimpulkan bahwa ada hubungan yang negatif antara gangguan kecemasan dengan hasil belajar siswa.

Selanjutnya hasil analisis data menunjukkan bahwa variabel gangguan kecemasan (X) terhadap hasil belajar (Y) Tabel 6. Hasil Uji t memiliki pengaruh sebesar 0,98 atau $98 \%$, sedangkan $2 \%$ tersebut dipengaruhi oleh faktor-faktor lain.

Uji $\mathrm{t}$ digunakan untuk mengetahui apakah variabel gangguan kecemasan terhadap variabel hasil belajar siswa berpengaruh secara signifikan. Cara menganalisis Uji t adalah membandingkan nilai signifikansi $<0,05$ $(\alpha=5 \%)$. Berikut hasil uji t menggunakan SPSS 23 for windows dapat dilihat pada Tabel 6 .

\begin{tabular}{|c|c|c|c|c|c|c|}
\hline \multicolumn{7}{|c|}{$\mathrm{ANOVA}^{\mathbf{a}}$} \\
\hline & & Sum of Squares & $\mathrm{df}$ & Mean Square & $\mathrm{F}$ & Sig. \\
\hline \multirow[t]{3}{*}{1} & Regression & .005 & 1 & .005 & 5.993 & $.018^{b}$ \\
\hline & Residual & .046 & 55 & .001 & & \\
\hline & Total & .051 & 56 & & & \\
\hline
\end{tabular}

a. Dependent Variable: Hasil Belajar

b. Predictors: (Constant), Gangguan Kecemasan

Berdasarkan Tabel 6 dapat dijelaskan bahwa hasil Uji $\mathrm{t}$ diperoleh sebesar 0,018 dengan signifikansi sebesar 0,000. Hal ini menunjukkan $0,018<0,05$ berarti variabel gangguan kecemasan berpengaruh secara signifikan terhadap hasil belajar siswa. Hal ini dapat dikatakan bahwa gangguan kecemasan akan berakibat pada peningkatan hasil belajar siswa kelas XI SMK Negeri 1 Makassar.

\section{KESIMPULAN}

Berdasarkan hasil analisis data dan pembahasan yang diuraikan, mengenai pengaruh gangguan kecemasan terhadap hasil belajar siswa pada mata pelajaran akuntansi kelas XI SMK Negeri 1 Makassar, maka dapat disimpulkan bahwa terdapat pengaruh negatif dan signifikan antara gangguan kecemasan terhadap hasil belajar siswa pada mata pelajaran akuntansi kelas XI SMK Negeri 1 Makassar. Hal ini ditunjukkan pada data penelitian bahwa kecenderungan variabel gangguan kecemasan berada pada $61,4 \%$ atau berada pada kategori cukup.

\section{REFERENSI}

Arikunto. 2001. Dasar-dasar Evaluasi Pendidikan. Jakarta: BumiAksara.

Atkinson. 2001. Pengantar Psikologi. Jilid Dua. AlihBahasa: Widjaja Kusuma. Batam: Interaksara.

Dacey. 2000. Your Anxious Child: How Parents and Teachers Can Relieve Anxiety In Children. San Fransisco: Jossy-Bass Publishers.

Djamarah. 2006. Strategi Belajar Mengajar. Jakarta: PT. RinekaCipta

Duwi, Priyanto. 2013. SPSS 22 Pengolahan Data Terpraktis. Jakarta: SalembaEmpat.

Elliott. 2000. Educational Psychology. Second Edition. Madition : Brown dan Benchmark Company.I 
Nuraisyiah, Nurdiana, Muhammad Imam Ma'ruf, Pengaruh Gangguan... $\mid 15$

Fausiah, Fitri. 2014. Psikologi Abnormal Klinis

Dewasa. Jakarta: Universitas Indonesia.

Hamalik, Oemar. 2006. Pendidikan Guru Berdasarkan Pendekatan Kompetensi. Jakarta: BumiAksara.

King, Laura. 2010. Psikologi Umum. Jakarta : Salemba Humanika.

Margono. 2010. MetodePenelitian Pendidikan. Jakarta: Rineka Cipta.

Nevid, Rathus. 2003. Psikologi Abnormal Edisi Kelima. Jakarta: Erlangga.

Nur, Yessy. 2015. Psikologi Pendidikan. Yogyakarta: Parama Publishing.

Poerwadarminto. 2012. Kamus Umum Bahasa Indonesia. Solo: PT.Tiga Serangkai Pustaka Mandiri.

Prawitasari, Johana. 2012. Psikologi Terapan. Jakarta: Erlangga

Rahmatullah. (2018). Pembelajaran Ekonomi

Berjatidiri Bangsa. JEKPEND: Jurnal

Ekonomi Dan Pendidikan, 1(1), 10.

https://doi.org/10.26858/jekpend.v1i1.505 5

Ridwan \& Akdon.2009. Pengantar Statistika Sosial. Bandung: Alfabeta.

Ruhimat, Toto dkk. 2013. Kurikulum \& Pembelajaran. Jakarta: Rajawali Pers.

Slameto. 2010. Belajar dan Faktor-faktor Yang Mempengaruhinya. Jakarta: PT RinekaCipta
. 2013. Belajar dan Faktor-faktor Yang Mempengaruhinya. Jakarta: PT Rineka Cipta

Sudjana, nana. 2013. Penilaian Hasil Proses Belajar Mengajar. Bandung: Remaja Rosdakarya

Sugiyono. 2010. Staristika Untuk Penelitian. Bandung: Alfabeta.

. 2015. Metode Penelitian Kuantitatif Kualitatif dan R \& D. Bandung: Alfabeta.

Susanto, Ahmad. 2013. Teori Belajar dan Pembelajaran di Sekolah Dasar.Jakarta: Kencana

Syah, Muhibbin. 2013. Psikologi Belajar. Jakarta: Rajawali Pers.

Wiramihardja, Sutardjo. 2010. Pengantar Psikologi Abnormal. Bandung: RefikaAditama .

Yudhawati, Ratna. 2011. Teori-teori Dasar Psikologi Pendidikan. Jakarta: Prestasi Pustaka Raya 